\title{
Spatial Color Analysis of Kindergarten Interior Design Based on Children's Psychological Activities in Digital Environment
}

\author{
Shan Xiaoxian ${ }^{1}$, Wan Meicheng ${ }^{2}$ \\ ${ }^{1}$ Jingdezhen Ceramic InstituteJingdezhen Ceramic Institute \\ ${ }^{2}$ Jingdezhen Planning Information Research Center
}

\begin{abstract}
In the digital environment, the kindergarten interior design should also be adjusted, and more attention should be paid to the spatial color matching. The progress of science and technology makes the comfort of children's living environment also increase. Designers should be aware of the importance of spatial color to children's physical and mental growth when designing the kindergarten interior. Therefore, this paper first analyzes the present situation of kindergarten interior color design in China under the digital environment from the perspective of children's color psychology, then puts forward the basic ideas of kindergarten interior color design according to space color psychology, and finally discusses the design methods of kindergarten interior color according to children's psychological activities, hoping to provide good living, entertainment and learning space for children's healthy development.
\end{abstract}

\section{Introduction}

The interior design of kindergarten must meet the physical and mental requirements of children and meet the educational goals of kindergarten. In this case, it is necessary to create a safe, healthy and rich indoor environment for children. Under the digital environment, the color design of kindergarten interior space needs to pay attention to the comfort level of children in space. Designers should not only master the interior design knowledge, but also understand the psychological development law of children in order to create a good learning and living environment.

\section{Children's Color Psychology}

Psychological research has proved that spatial color environment has an important influence on people's emotion, intelligence and personality development. Italian preschool educator Maria Montessori pointed out that children's understanding of the objective world begins with perception, and because of the existence of feeling and perception, one can acquire knowledge about the objective world, thus laying the foundation for advanced and complex psychological activities. The eyes are the window to know the world, and the vision occupies the main position in the five senses of the body. As pointed out in Lefrancois's Child Development Psychology, babies aged 1 to 7 days can distinguish high purity white, red, green and yellow, and babies aged 4 months can not only distinguish colors, but also form a love for colors [1]. The research also shows that children's color preference is closely related to their emotions and personality, which reflects children's psychological feelings, such as happiness or sadness. Thus, as the living space of preschool children, the color design of kindergarten is very important.

\section{Analysis on the Present Situation of Color Design in Kindergarten Indoor Space in China under Digital Environment}

\subsection{There is a deviation between spatial color design and children's psychological needs}

In kindergarten interior space, many kindergarten space designs can no longer meet the psychological development needs of children. Some inner spaces of kindergartens are even designed according to the space of adults, which is an open space for children and will make them feel strange [2]. Therefore, the design of kindergarten interior space should consider children's psychological development needs and should be designed according to children's particularity. In particular, it is necessary to pay attention to children's visual effects and psychological feelings in spatial color design.

\subsection{Pay too much attention to beautiful color design}

In kindergarten interior design, color rendering is a common design technique. However, many kindergartens in China use color inappropriately in their design, and place too much emphasis on the use of beautiful colors. For example, the interior design of some kindergartens 
uses high brightness and high purity colors, which is very unfavorable to children's growth. These colors stimulate children's vision and psychology, and easily make children feel tired and cause psychological discomfort.

\section{Basic ideas of color design in kindergarten interior space under Digital Environment in Digital Environment}

\subsection{Design ideas}

In the digital environment, the color design of kindergarten interior space should be based on comfort and cheerfulness, and the interior space should not bring oppressive feeling to children, but make them in a relaxed state, making them happier physically and mentally[3]. Therefore, the color design of kindergarten interior space should follow the law of children's physical and mental development, and then create a comfortable environment for children to grow up.

\subsection{Color psychology}

Kindergarten interior designers should apply the knowledge of color psychology to kindergarten interior design, because different colors will make people have different emotional tendencies, and early childhood is the most important stage of children's growth, as well as the enlightenment stage of children's cognitive ability, inner emotion and thinking ability. As we all know, color has an edifying effect on children, which can cultivate children's association ability and help children's thinking ability to develop continuously. Therefore, kindergarten interior design should use the color tone to increase the artistic atmosphere of interior environment, so as to improve children's aesthetic cognitive ability.

\section{The significance of spatial color design base on children's psychological activities}

\subsection{Improve the quality of preschool education}

In modern interior space design, color plays an important role, which can create a good environment and influence people's behavior and thinking imperceptibly. Children's subjective consciousness of color reaction is strong, so it is suggested that the color of kindergarten interior space should be warm [4]. In addition, for kindergarten education, the rational distribution of spatial colors is beneficial to children's physical and mental health and can build a positive learning atmosphere for children. Generally speaking, the color design of kindergarten space needs to conform to children's growth rules and hobbies, and children like bright and brighter colors, which can stimulate children's imagination, develop children's thinking ability and effectively guide children's independent activities, which is of great help to improve the quality of early childhood education.

\subsection{Highlight the people-oriented concept}

In kindergarten, the concept of people-oriented should be highlighted in the color design of interior space, and the design activities should be carried out around early childhood education. Color changes should be used to enrich the interior space and make children's awareness of space colors become strong, which can make the space function more humanized. Designers should fully consider the collocation of colors, rationally adjust the spatial layout and give children a good visual and psychological feeling. Color design should also pay attention to the style and color matching of furniture and decorative materials, adjust the interior light to the best, comprehensively analyze the color matching and spatial details, and provide a good living and learning environment for children.

\section{Color design strategy of kindergarten interior space in Digital Environment}

\subsection{Overall color relationship}

Children's psychology research shows that 3-year-old preschool children can't distinguish different colors well, 4-year-old children's ability to distinguish different colors gradually improves, 5-year-old children have been able to notice color saturation, and 6-7-year-old children are more capable of distinguishing subtle differences in color saturation [5]. It can be seen that children's cognitive ability of color in early childhood is gradually improving, so it is necessary to help children form color vision in kindergarten interior design. The interior color design of kindergarten doesn't have to be colorful, but it must be full of children's fun. The basic element of interior space should be bright color matching, and the overall color tone should be bright and lively, reflecting the positive and cheerful spirit, but this does not mean that a large number of colors should be integrated into a space. Because long-term exposure to excessively bright colors will affect children's eyesight and distract children's attention. Therefore, we should mainly use some bright colors to determine the overall color tone, so that the overall effect is harmonious. It is best not to match more than three colors, and then carry out the color matching design of local themes. Besides determining the color tone, we should also consider local decoration. On the one hand, high saturation tones such as "red, yellow and blue" can be used as the main colors, highlighting the main entrance and space division, so that the whole space has a jumping degree; On the other hand, the color is light or wood, and then furniture or decoration is used to increase the sense of space.

\subsection{Multi-functional game space color}

Children's activities include study, play and life. Children's behavior development is mainly cultivated in games, through which children's language communication ability, physical coordination ability and logical thinking ability can be cultivated [6]. Children 
grow up with strong curiosity, they are active and playful, and they have more behaviors in daily games, such as crawling, running and jumping. Compared with adults, children like small spaces. Designers can take advantage of children's preferences and incorporate cave design elements (as shown in Figure 1), which not only plays the role of space division, but also meets children's daily game needs, and increases the interest of interior space. In terms of space color, in order to achieve a warm effect in the game space, it is necessary to use warm or light floors for paving. In addition, some kindergartens are piled up in wall decoration, leaving no room for children to create and play freely. Children often like painting on the wall, which is usually prevented, but painting is a way for children to express their inner world. Painting on paper can also meet children's needs, but painting on the wall highlights children's nature and should not restrict children's individualized development. Therefore, kindergartens can design a wall for children to paint, such as reserving painting space in corridors and designing multi-functional rooms (as shown in Figure 2). Painting around the wall can be designed in the form of stickers, and can be set off with more bright colors.

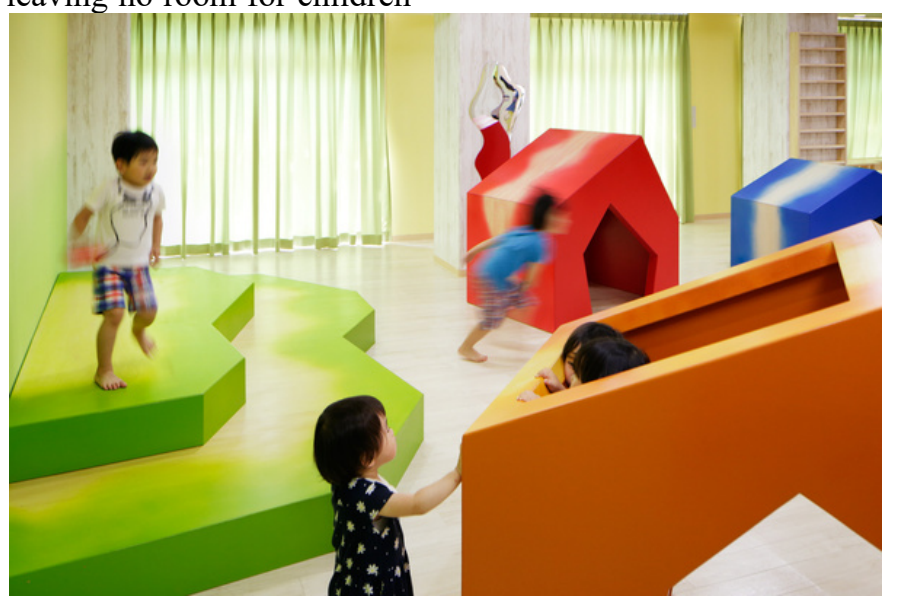

Figure 1 CAVE SPACE

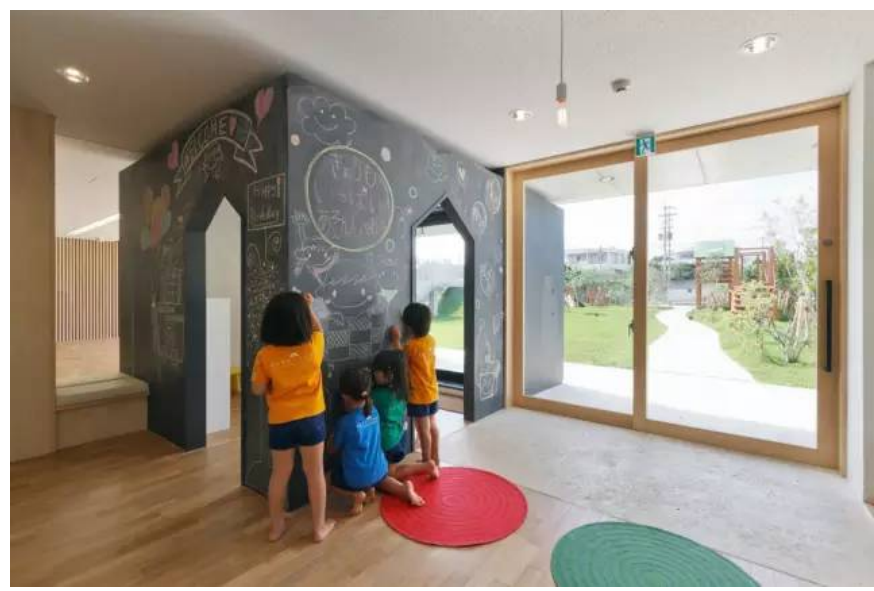

Figure 2 Graffiti Space

\subsection{Exchange space color}

Children entering kindergarten is a process of experiencing collective life, and communication with teachers and students is of great significance for children's development, so kindergarten interior design should pay attention to creating affinity atmosphere [7]. In space design, it is necessary not only to meet the needs of children's learning and activities, but also to design communication space. For young children, they are always accompanied by their parents before entering kindergarten, which has strong dependence, and they will inevitably have fear when entering kindergarten. These problems should be considered in space function and space color design. On the one hand, children's panic is due to psychological fear and incompatibility; On the other hand, when children cry, they don't want others to interfere with their emotions, and their hearts are in an unsafe state. It has been observed that a quiet and pleasant environment can relieve anxiety. Therefore, we should design parent-child space or communication space in kindergarten to relieve children's discomfort to unfamiliar environment. The exchange of color emotion in space should be based on soothing mood, which can adopt relatively neutral tone, and the furnishings can be set off with green, so as to appropriately increase the natural atmosphere and build a comfortable space environment and color emotion. 


\section{CONCLUDING REMARKS}

In the digital environment, designers need to deeply understand the relationship between children's psychological activities and kindergarten space color. Designers can realize the significance of children's space color demand, and children's growth environment should follow its physical and mental development law.

\section{REFERENCES}

1. Wang Haoyu. Color Design of Kindergarten Interior Space Based on Children's Psychological Activities[J]. Shanxi Architecture, 2018, 44(23): 16-17.

2. Xi Luyue, Guo Yuanyuan. Research on Spatial Color of Kindergarten Interior Design Based on
Children's Psychological Activities[J]. Building Materials and Decoration, 2018, (4):93.

3. Feng Xianjing. Influence of Children's Color Psychology on Children's Space Design[J]. Popular Literature and Art, 2018, (12): 57-58.

4. Zhang Ning. Design of Interior Space Environment in Kindergarten[J].Online Education,2012,(21):127.

5. Wang Xuan. Exploring the Relationship between Kindergarten Interior Design and Early Childhood Education $[\mathrm{J}]$. Decoration Refurbishment Centre, 2020, (1): 199.

6. Han Qiuyue. Kindergarten Interior Design Based on Child Psychology[J]. Beauty and Times, 2017, (10): 77-79.

7. Liu Qiang, Shen Jingjing. Application of Color in Kindergarten Environmental Design[J]. Arts In China, 2019, (10): 283-28 